\title{
Sinais bimanuais da Libras: um estudo da produção de sinais realizados no subespaço "costas da mão" do parâmetro locação
}

\author{
Libras' bimanual signs: a study regarding the production of signs \\ realized in the subspace "back of the hand" of the location parameter
}

\author{
Valéria Simplício da Silva ${ }^{1}$ \\ Edivaldo da Silva Costa ${ }^{2}$ \\ Margarida Maria Teles ${ }^{3}$
}

DOI: 10.28998/2317-9945.2019n63p106-119

\begin{abstract}
Resumo
O objetivo deste artigo foi realizar uma análise de como se apresentam os sinais da Lingua Brasileira de Sinais (Libras) pelos sinalizadores surdos de Sergipe, produqidos com as duas mãos, em que a mão ativa configura o sinal e a passiva serve de apoio para o sinal configurado, no subespaço "costas da mão", da locação "mão de apoio". Esse estudo teve como metodologia a pesquisa bibliográfica, utilizando como principais bases teóricas os estudos linguísticos de Quadros e Karnopp (2004), Felipe (1998), Brito (1998) e Karnopp (1999), e a pesquisa de campo, por meio da observação direta da sinalização dos participantes e do vídeoregistro das variantes que ocorrem na forma como se apresenta o subespaço "costas da mão", da locação mão de apoio, na produção dos sinais, identificando se a frequência é maior na forma de mão aberta ou fechada. Os resultados encontrados nesta pesquisa nos levaram a uma análise de que as variações que ocorrem na forma da mão do subespaço "costas da mão" quando um sinal é produzido sobre ela podem se caracterizar como um alofone, uma vez. que essas variações não alteram o sentido nem o significado dos sinais.
\end{abstract}

Palavras-chave: Costas da mão. Locaşão. Mão de apoio. Variação fonológica.

\begin{abstract}
The aim of this article was to perform an analysis of how the signs of the Brazilian Sign Language (Libras), produced with two hands, in which the active hand configures the sign and the passive one works as a support for the configured sign, in the subspace "back of the hand", of the location "band of support", are used by the deaf people from Sergipe. The methodology of this study is the bibliographic research, using as main theoretical framework the linguistic studies by Quadros and Karnopp (2004), Felipe (1998), Brito (1998) and Karnopp (1999), and the field research, using the direct observation of the participants signing and the videorecording of the variants that occur in the way the subspace "back of the hand", of the hand support location, is presented in the production of the signs, in order to identify if the frequency is greater in the form of hand open or closed. The results found in this research led us to conclude that the variations that take place in the form of the hand of the subspace "back of the hand", when a sign is produced on it, can be characterized as an allophone, since these variations do not alter the sense and meaning of the signs.
\end{abstract}

Keywords: Back of the hand. Location. Support hand. Phonological variation

\footnotetext{
${ }^{1}$ Doutoranda em Educação pela Universidade Federal da Bahia. Mestre em Educação pela Universidade Federal de Sergipe. Professora Assistente do Departamento de Letras Libras da Universidade Federal de Sergipe.

${ }^{2}$ Doutor em Educação pela Universidade Federal de Sergipe. Professor Adjunto do Departamento de Letras Libras da Universidade Federal de Sergipe.

${ }^{3}$ Mestre em Educação pela Universidade Federal de Sergipe. Professora Assistente do Departamento de Educação da Universidade Federal de Sergipe.
} 
Recebido em: 12/02/2019.

Aceito em: 19/05/2019.

\section{Introdução}

Este artigo é resultado de uma atividade de pesquisa realizada na disciplina Fonética e Fonologia da Libras do Curso de Licenciatura em Letras Libras da Universidade Federal de Sergipe (UFS), ministrada no período de janeiro a maio de 2016. A pesquisa se constituiu em observações e registros realizados a partir da sinalização de usuários surdos proficientes da Libras, sob a análise de um de seus parâmetros fonológicos, utilizado na produção do sinal: a "Locação", também nomeada de "Ponto de articulação". Teve como objeto de estudo o subespaço "costas da mão", da Locação "mão de apoio" (mão que apoia a mão ativa durante a produção do sinal), também denominada de "mão passiva".

Assim, este estudo se propôs a realizar os seguintes questionamentos: a forma da mão que é utilizada pelos sinalizadores surdos sergipanos, usuários da Libras, para apoiar o sinal quando ele é realizado no subespaço "costas da mão", é configurada, frequentemente, mais de forma aberta ou fechada? As variações que ocorrem na forma da mão (aberta ou fechada) do subespaço "costas da mão", da Locação "mão de apoio", podem ser consideradas variações de um mesmo fonema?

Figura 1: Exemplos de sinais produzidos nas costas da mão fechada e aberta, respectivamente.

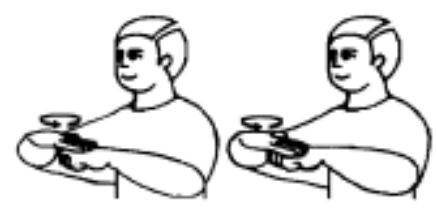

Conversar

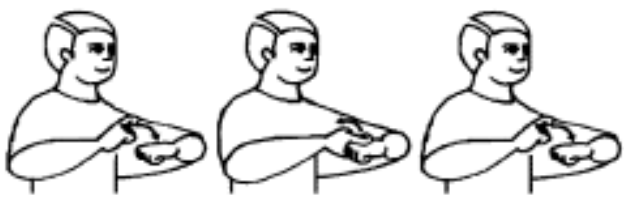

Duro

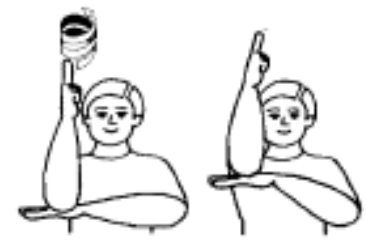

Alto

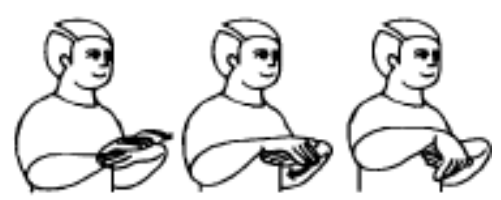

Noite

Fonte: Capovilla, Maurício e Raphael (2011, p. 673; p. 866; p. 1586).

O objetivo foi verificar se a forma da mão que é utilizada pelos sinalizadores surdos da Libras em Sergipe, para apoiar o sinal quando ele é realizado no subespaço "costas da mão", é configurada, mais frequentemente, de forma aberta ou fechada, fazendo a descrição e a análise dessas formas.

A necessidade, importância e a relevância deste estudo advêm dos questionamentos dos aprendizes iniciantes ouvintes da Libras, como segunda língua, com relação à forma da referida mão ao realizar o sinal. Ou seja, se ela deve ser configurada aberta ou fechada, quando o sinal é realizado no subespaço "costas da mão". Segundo a psicóloga Walkíria Duarte Raphael, estudiosa da Libras, em entrevista (DEFICIENTE ONLINE, 2018) a maioria dos sinais são realizados, no Rio de Janeiro, com a mão de apoio fechada. Já em São Paulo, a mão de apoio é aberta. 
Nos estudos linguísticos da Libras, dentre os subespaços dos sinais produzidos nas costas da mão que apoia o sinal, não é realizada nenhuma referência quanto à forma "aberta ou fechada", no entanto, as duas formas têm sido utilizadas pelos usuários da Libras no Brasil. Neste contexto, vemos a relevância de realização deste estudo. Entretanto, para apoiar o entendimento sobre esta temática, primeiramente revisitaremos conhecimentos já socializados sobre os parâmetros de análise sublexical dos sinais, que vêm sendo referidos na literatura sobre a fonologia das línguas de sinais, de forma a contextualizar a mão de apoio como sendo um desses parâmetros, que é a Locação.

Com base nos estudos fonético-fonológicos, a pesquisa realizada por Xavier e Barbosa (2014) também discute casos da variação na CM da mão passiva com base em dados de 12 surdos paulistas e 60 sinais da Libras. Este estudo confirmou a ocorrência da variação de parâmetros articulatórios na sinalização, demonstrando que os itens lexicais constituem unidades distintas e que estas, por sua vez, podem apresentar variações em sua manifestação concreta.

\section{O nível fonológico da Libras: as unidades de análise sublexical propostas para as línguas de sinais}

A Libras possui todos os níveis linguísticos: fonológico, morfológico, sintático, semântico e pragmático e uma estrutura gramatical própria, adequada para transmitir informações necessárias ao processo de comunicação e ensino. De acordo com Brito:

A Libras é dotada de uma gramática constituída a partir de elementos Constitutivos das palavras ou itens lexicais e de um léxico que se estruturam a partir de mecanismos fonológicos, morfológicos, sintáticos e semânticos que apresentam também especificidades, mas seguem também princípios básicos gerais. É dotada também de componentes pragmáticos convencionais codificados no léxico e nas estruturas da LIBRAS e de princípios pragmáticos que permitem a geração de implícitos sentidos metafóricos, ironias e outros significados não literais (BRITO, 1998, p. 23).

As diferenças que existem entre as línguas de sinais e as línguas orais referem-se à modalidade de percepção e produção, no entanto o termo "fonologia" tem sido utilizado para referir-se também ao estudo dos elementos básicos das línguas de sinais. Segundo Quadros \& Karnopp (2004), para marcar essas diferenças, o linguista e pesquisador norteamericano William C. Stokoe Jr., em 1960, propôs o termo "quirema"4 às unidades formacionais dos sinais (configuração de mão, locação e movimento) e, ao estudo de suas combinações, o termo "quirologia" (do grego, Quir significa mão). No entanto, outros pesquisadores, e o próprio Stokoe, em estudos posteriores ao ano de 1978, têm utilizado o termo "fonema" e "fonologia" estendendo seus significados, de modo a abarcar a realização linguística visual-espacial, uma vez que as línguas de sinais, como todas as línguas orais, assim como quaisquer línguas naturais, apresentam princípios que são subjacentes aos seus sistemas linguísticos particulares, apesar das diferenças de superfície entre palavras/oral e o sinal/visual.

\footnotetext{
${ }^{4}$ Quiremas são as unidades mínimas sinalizadoras que combinadas formam os sinais e estabelecem alguns padrões possíveis de combinações entre as unidades e as variações no ambiente fonológico, estes correspondem aos fonemas nas línguas orais (QUADROS; KARNOPP, 2004).

${ }^{5}$ Comunicação por meio de sinais feitos com os dedos.
} 
Stokoe propôs um esquema linguístico estrutural para analisar as formas dos sinais e propôs a decomposição dos sinais na ASL (American Sign Language - Língua de Sinais Americana) em três principais aspectos ou parâmetros que não têm significado isoladamente. São eles: Configuração de mão (CM), Locação da mão (L) e Movimento (M). Em análises das unidades mínimas formacionais dos sinais, posteriores à de Stokoe, a partir da década de 1970, os linguistas Robbin Battison (1974) e Edward S. Klima e Ursulla Bellugi (1979) propuseram a adição de informações referentes à orientação da mão (Or) e aos aspectos não manuais dos sinais (ANM), que são as expressões faciais e corporais. Estes dois parâmetros foram então adicionados aos estudos da quirologia de sinais. Assim, resumidamente, segundo Quadros e Karnopp, temos:

1 - Configuração das mãos: são formas das mãos, que podem ser da datilologia (alfabeto manual) ou outras formas feitas pela mão dominante, ou pelas duas mãos do emissor ou sinalizador.

2 - Ponto de articulação: é o lugar onde a mão dominante configurada faz o sinal, podendo esta tocar alguma parte do corpo ou estar em um espaço neutro vertical (do meio do corpo até a cabeça) e horizontal (à frente do emissor).

3 - Movimento: os sinais podem ter um movimento ou não.

4 - Orientação: os sinais podem ter uma direção e a inversão desta pode significar ideia de oposição, contrário ou concordância número-pessoal.

5 - Expressão facial e/ou corporal: muitos sinais, além dos quatro parâmetros mencionados acima, em sua configuração têm como traço diferenciador também a expressão facial e/ou corporal (QUADROS; KARNOPP, 2004, p. 29-30).

Portanto, CM, L, M, Or e ANM são os parâmetros fonológicos das línguas de sinais, ou seja, as unidades mínimas (fonemas) que constituem morfemas nas línguas de sinais, de forma análoga aos fonemas que constituem os morfemas nas línguas orais, e, na combinação de quatro ou cinco parâmetros tem-se o sinal. Além dos aspectos levantados por Stokoe (1960), outro aspecto que também assemelha as línguas de sinais às línguas orais, do ponto de vista fonológico, refere-se ao fato de que na realização de seus itens lexicais, ou seja, na pronúncia dos sinais, pode ocorrer variação.

Durante a formação dos sinais, existem restrições quirológicas requeridas para uma boa formação. Os sinais podem ser produzidos da seguinte forma: i) condição de simetria, produzidos pelas duas mãos, em que ambas são ativas e simétricas; ii) condição de dominância, com uma das mãos ${ }^{6}$ ou com as duas mãos, em que uma é ativa (realiza o sinal) e a outra é passiva (apoia o sinal) servindo como locação ou ponto de articulação. De acordo com Quadros e Karnopp:

Os articuladores primários das línguas de sinais são as mãos, que se movimentam no espaço em frente ao corpo e articulam sinais em determinadas locações nesse espaço. Um sinal pode ser articulado com uma ou duas mãos. Um mesmo sinal pode ser articulado tanto com a mão direita quanto com a esquerda; tal mudança, portanto, não é distintiva. Sinais articulados com uma mão são produzidos pela mão dominante (tipicamente a direita para destros e a esquerda para canhotos), sendo que sinais articulados com as duas mãos também ocorrem e apresentam

\footnotetext{
${ }^{6}$ De acordo com Xavier (2006), há casos de certos sinais na Libras que são classificados como sendo produzidos com uma mão, mas que também são articulados com duas e vice-versa.
} 
restrições em relação ao tipo de interação entre as mãos (QUADROS; KARNOPP, 2004, p. 51).

Dentre os três tipos de produção de sinais descritos segundo as autoras acima citadas, foram selecionados, para esta pesquisa, sinais produzidos com as duas mãos, em que uma é ativa e a outra serve como locação.

\section{A Locação "mão de apoio" na produção do sinal: sinais produzidos no subespaço "costas da mão"}

A Locação, também denominada de Ponto de articulação, é considerada uma das três principais unidades formacionais dos sinais, apesar de não haver muitos estudos sobre ela. É o ponto ou o local onde é articulado o sinal, ou seja, o ponto de articulação onde o sinal é produzido. É numa determinada área, denominada espaço de enunciação, que estão contidas as quatro grandes e principais locações, ou seja, os quatro pontos de articulação, dentro do raio de alcance das mãos, em que os sinais da Libras devem ser articulados (QUADROS; KARNOPP, 2004). O espaço de enunciação é visto como um espaço ideal, uma vez que considera que os interlocutores estejam face a face (KARNOPP, 1999).

Dentro desse número limitado ou finito de locações, que são: cabeça, tronco, espaço neutro e mão passiva, existem subespaços dentro dessas quatro grandes locações, sendo que algumas são mais exatas e outras mais abrangentes. O quadro a seguir mostra essa descrição e diferenciação entre as principais locações e os subespaços.

Quadro 1 - as quatro Locações e seus respectivos 56 subespaços da Libras.

\begin{tabular}{|c|c|}
\hline Cabeça (C) & Tronco (T) \\
\hline Topo da cabeça $(\bar{V})$ & $\operatorname{Pescoço~}(\mathrm{P})$ \\
\hline Testa $(\mathrm{T})$ & Ombros $(\mathrm{O})$ \\
\hline Rosto (R) & Busto (B) \\
\hline Parte superior do rosto $(\mathrm{S})$ & Estômago (E) \\
\hline Parte inferior do rosto (I) & Cintura $(\mathrm{C})$ \\
\hline \multicolumn{2}{|l|}{ Orelhas (p) } \\
\hline Olhos $(\mathrm{O})$ & Braços (B) \\
\hline $\operatorname{Nariz}(\mathrm{N})$ & Parte superior do braço (S) \\
\hline Boca (B) & Antebraço (I) \\
\hline Bochechas (d) & Cotovelo $(\mathrm{C})$ \\
\hline Queixo (Q) & Pulsos (P) \\
\hline Zona abaixo do queixo (A) & Perna (p) \\
\hline Mão (M) & Espaço Neutro (EN) \\
\hline \multicolumn{2}{|l|}{ Palma (P) } \\
\hline \multicolumn{2}{|l|}{ Costas da mão (C) } \\
\hline \multicolumn{2}{|l|}{ Lado do indicador $\left(\mathrm{L}_{1}\right)$} \\
\hline \multicolumn{2}{|l|}{ Lado do dedo mínimo $\left(\mathrm{L}_{2}\right)$} \\
\hline \multicolumn{2}{|l|}{ Dedos (D) } \\
\hline \multicolumn{2}{|l|}{ Pontas dos dedos (Dp) } \\
\hline \multicolumn{2}{|l|}{ Nós dos dedos (junção entre os dedos e as mãos) } \\
\hline \multicolumn{2}{|l|}{ (Dd) } \\
\hline \multicolumn{2}{|l|}{ Nós dos dedos (primeira junta dos dedos) (Dj) } \\
\hline \multicolumn{2}{|l|}{ Dedo mínimo (D1) } \\
\hline \multicolumn{2}{|l|}{ Anular (D2) } \\
\hline \multicolumn{2}{|l|}{ Dedo médio (D3) } \\
\hline \multicolumn{2}{|l|}{ Indicador (D4) } \\
\hline Polegar (D5) & \\
\hline
\end{tabular}


Juntas dos dedos

Próximos aos pulsos

Interstícios entre os dedos (V)

Interstício entre os dedos polegar e o indicador (V1)

Interstício entre os dedos indicador e médio (V2)

Interstício entre os dedos médio e anular (V3)

Interstício entre os dedos anular e mínimo (V4)

Fontes: Ferreira-Brito; Langevin (1995); Quadros; Karnopp (2004).

Dentre os 11 subespaços da Locação "mão de apoio", descritos no quadro acima, "costas da mão" foi o objeto deste estudo, sob a análise dos sinais produzidos sobre essa locação. Para tanto, foi realizado um registro das variantes que ocorrem nesta configuração da mão.

\section{Metodologia}

Para realização deste estudo, primeiramente foram pesquisados 32 sinais bimanuais (produzidos com as duas mãos), em que uma é ativa e a outra serve como locação. Todos esses sinais têm como subespaço da "mão de apoio" para produção do sinal, as "costas da mão", conforme o quadro 1.

Em seguida foi realizada a coleta de dados, que consistiu no registro da produção dos 32 sinais. Essa coleta foi realizada pelos alunos da disciplina Fonética e Fonologia da Libras, do Curso de Licenciatura em Letras Libras da UFS, por meio de uma atividade de pesquisa da disciplina.

A turma, que era composta por 22 alunos, foi dividida em duplas e, para cada uma dessas, foi definido um número de três surdos a serem filmados. Uma das duplas conseguiu coletar os dados com apenas dois sinalizantes surdos, devido à dificuldade de acesso a eles por parte dos alunos. Totalizando, assim, um número de 32 participantes. O número de sinalizantes da pesquisa justificou-se por ser uma quantidade razoável para os alunos, devido à dificuldade em encontrar surdos disponíveis para coleta das informações.

Como instrumento de coleta de dados, foi utilizado um quadro contendo uma lista de palavras, em ordem alfabética, transcritas na Língua Portuguesa, referentes aos sinais produzidos no subespaço "costas da mão". Os sinalizantes da pesquisa foram todos surdos de ambos os gêneros, usuários proficientes da Libras como primeira língua, com idade acima de 18 anos e residentes em cinco municípios de Sergipe: Aracaju, Laranjeiras, Nossa Senhora do Socorro, Lagarto e Itabaiana.

O quadro a seguir mostra a lista de palavras relativas aos sinais que foram pesquisados, bem como o número de sinalizantes e as formas da mão de apoio utilizadas na produção dos sinais. Esses sinais serão apresentados graficamente por meio do sistema de escrita de línguas de sinais SignWriting (SW) ${ }^{7}$.

\footnotetext{
${ }^{7}$ O SignWriting é uma escrita visual direta por meio da qual é possível ler e escrever línguas de sinais sem a necessidade de tradução para uma língua oral (BARRETO; BARRETO, 2012). É um sistema internacional e pode ser usado para escrever qualquer língua de sinais do mundo (SUTTON, 2003).
} 
A escolha do SW como sistema de representação gráfico-esquemática para os dados desta pesquisa fundamenta-se no estudo realizado por Costa (2014), o qual enfatiza que o sistema imagético fossilizado (desenhos e imagens reais) utilizado para registro das línguas de sinais não permite uma ideia integral do sinal, tampouco das articulações fonéticas e suas diferentes variações alofonéticas, por vezes tornando a leitura confusa, principalmente, por causa da utilização das setas de movimento. Mas a escrita de sinais permite tanto o mapeamento da estrutura interna do sinal, quanto o registro e a recuperação da informação com facilidade.

Quadro 2 - inventário de palavras propostas para os sinais pesquisados escritos pelo sistema de escrita de línguas de sinais SignWriting.

\begin{tabular}{|c|c|c|c|c|c|c|c|c|c|c|}
\hline & \multicolumn{6}{|c|}{$\begin{array}{l}\text { PRODDZDDOS } \\
\text { COM M MROO DE APOOLO ABERTA }\end{array}$} & 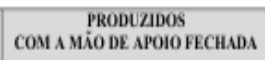 & $\begin{array}{l}\text { DICLONRRO } \\
\text { DETLLIBRAS }\end{array}$ & $\begin{array}{l}\text { SincLCOAM } \\
\text { Locicio }\end{array}$ & 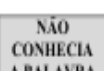 \\
\hline $\begin{array}{c}\text { PALLVRA } \\
\mathrm{s}\end{array}$ & $\begin{array}{ll}\text { OT. } \\
\text { INF }\end{array}$ & $\%$ & $\begin{array}{c}\text { SINAL } \\
\text { ESCRTO } \\
(\mathrm{SWW})\end{array}$ & $\begin{array}{l}\text { QT. } \\
\text { INF. }\end{array}$ & $\%$ & $\begin{array}{c}\text { SINA } \\
\text { BSCRTO } \\
\text { (SWI) }\end{array}$ & 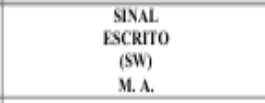 & $\begin{array}{c}\text { SIIAL } \\
\text { ESCRIMO } \\
\text { (SWW } \\
\text { M.F. }\end{array}$ & $\begin{array}{l}\text { OT. } \\
\text { INF. }\end{array}$ & $\begin{array}{l}\text { OT. } \\
\text { NNF. }\end{array}$ \\
\hline $\begin{array}{l}\text { AGIENIA } \\
\mathrm{R}\end{array}$ & 4 & 12,3 & $\stackrel{+1}{0}$ & 28 & 87,5 & 0 & 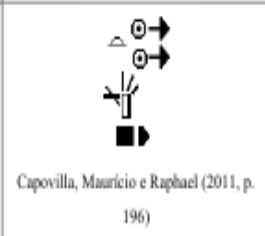 & & . & . \\
\hline 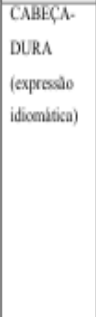 & 2 & 6,25 & 品 & ${ }^{30}$ & 93,78 & 炡 & . & 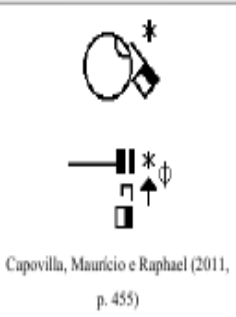 & . & . \\
\hline CAPIIALL & 2 & 6,25 & * & 30 & $9: 3,7$ & & . & 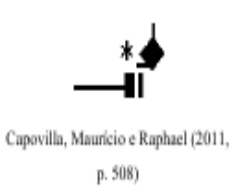 & - & . \\
\hline $\begin{array}{l}\text { CARRNHO } \\
\text { CARNHOS } \\
6 \\
6\end{array}$ & 9 & 28,12 & $\hat{\mathbf{D}}_{\odot \rightarrow}$ & 25 & 71,88 & $\hat{N}^{\circ}$ & $\stackrel{\stackrel{\theta \rightarrow}{\oplus \rightarrow}}{\stackrel{\theta \rightarrow}{\oplus}}$ & . & . & . \\
\hline
\end{tabular}

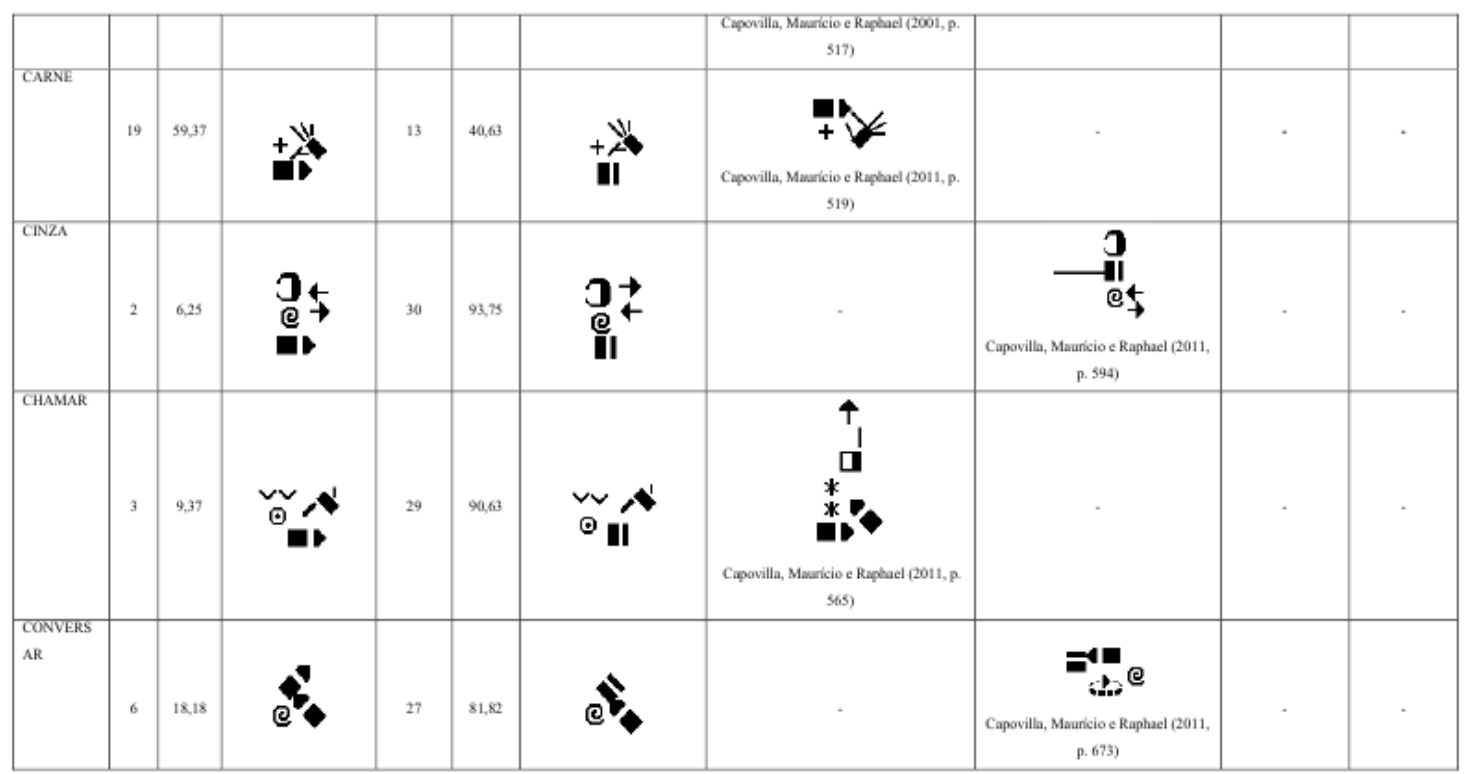




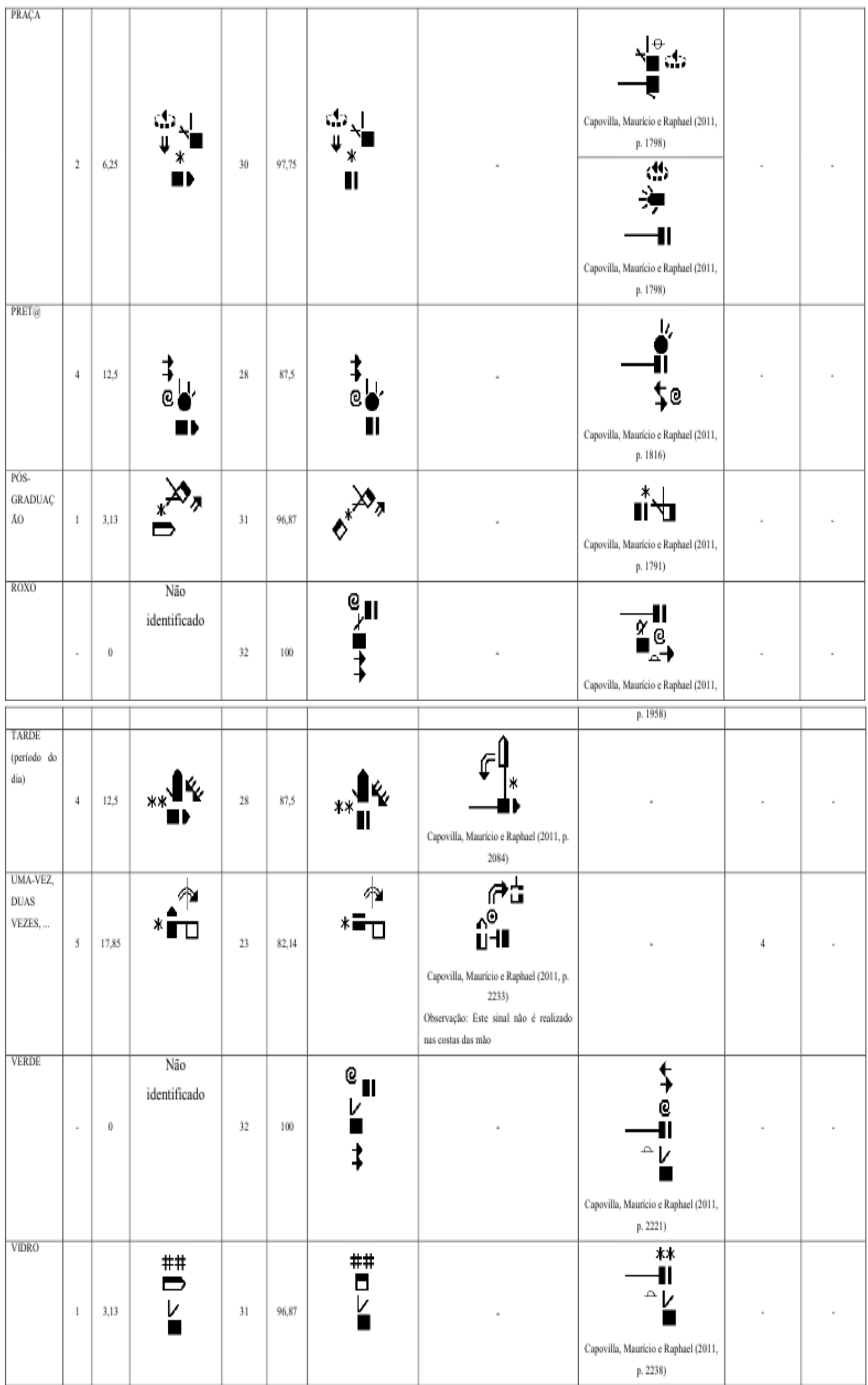




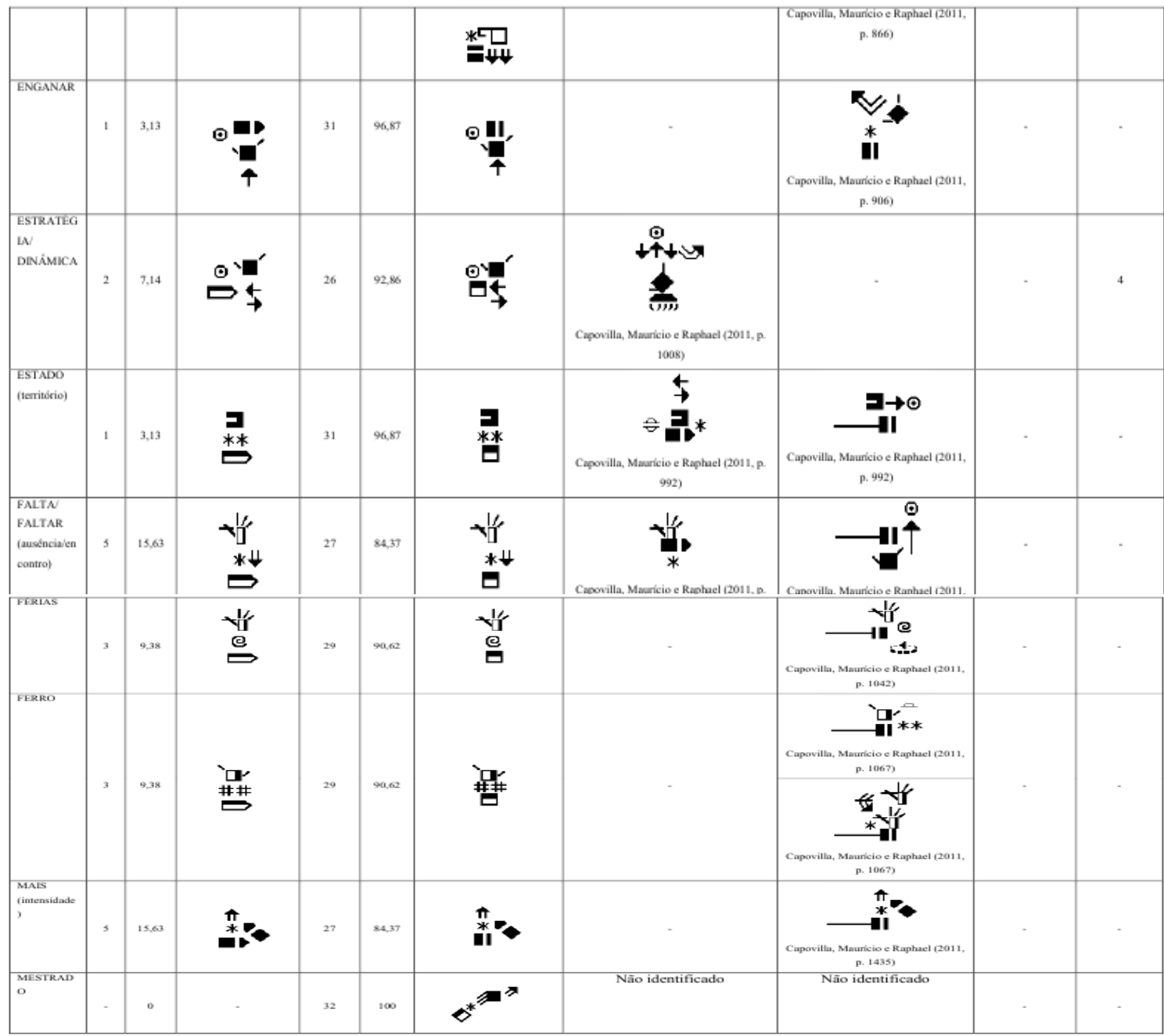

\begin{tabular}{|c|c|c|c|c|c|c|c|c|c|c|}
\hline $\begin{array}{l}\text { MATEMAT } \\
\text { ICA }\end{array}$ & 4 & 12,5 & $* *$ & 28 & 87,5 & & 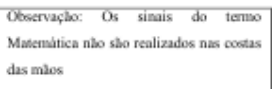 & 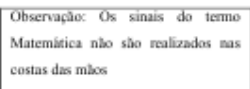 & . & - \\
\hline \begin{tabular}{|l|l|} 
NOITE \\
\end{tabular} & 1 & 3,13 & $\stackrel{\stackrel{e}{\mathbf{b}}}{\stackrel{\mathbf{b}}{\mathbf{b}}}$ & 31 & 96,87 & $\stackrel{e}{e}$ & 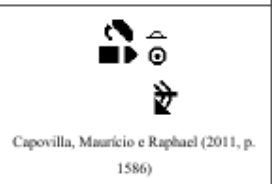 & - & . & - \\
\hline PAIS & 1 & 3,13 & $\underset{*}{4}+$ & 31 & 96,87 & $\begin{array}{r}* \\
\text { UI }\end{array}$ & - & 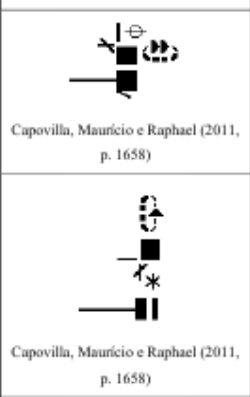 & . & . \\
\hline \begin{tabular}{|l|} 
PEDR \\
\end{tabular} & 1 & 3,13 & $* * *^{+}$ & 31 & 96,87 & $* *$ & . & $\underset{\substack{\text { Capovilla, Mauncio e Raphace (2011, } \\
\text { p. 1709) }}}{-\mathbf{n}}$ & . & - \\
\hline
\end{tabular}

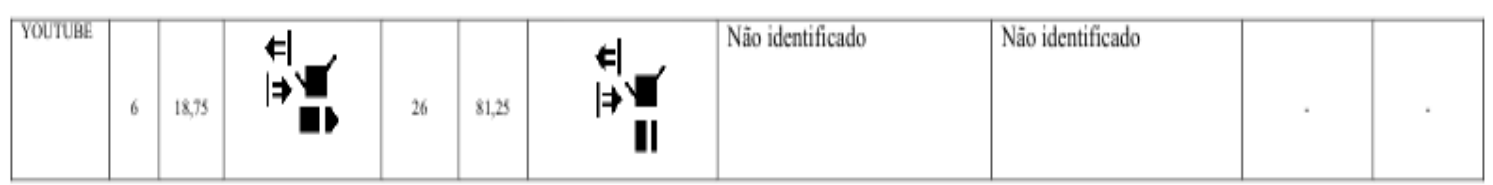




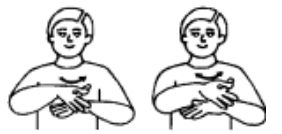

Aguentar

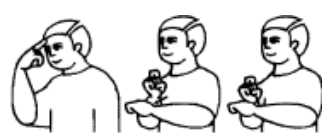

Cabeça Dura

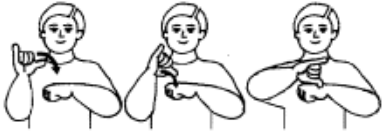

Capital

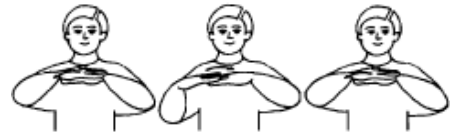

Carinho
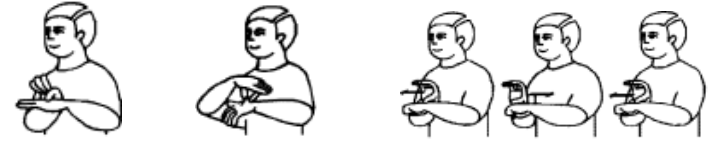

Cinza

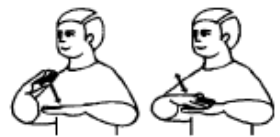

Chamar

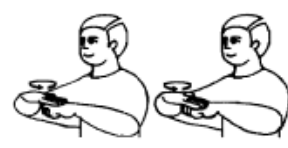

Conversar

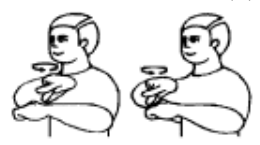

Carne (2)
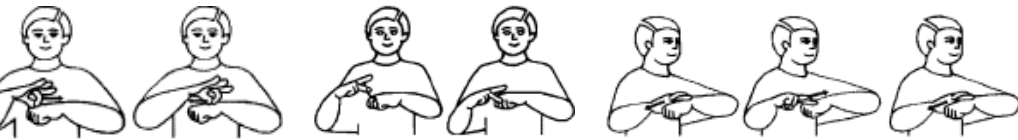

Praça

Preto

Pós-graduação

Roxo
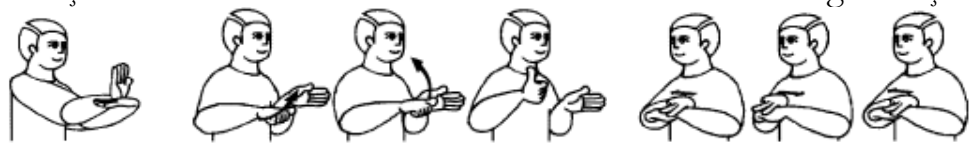

Verde

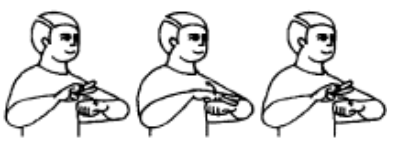

Vidro

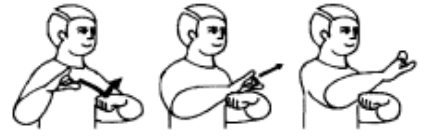

Enganar

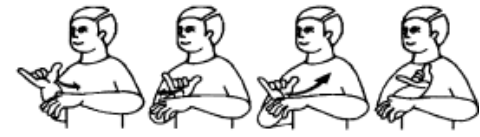

Estratégia

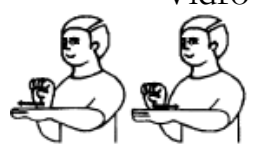

Estado

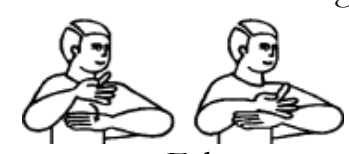

Faltar

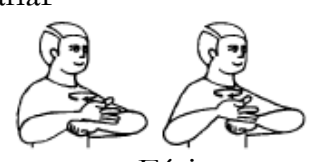

Férias

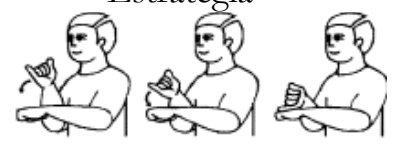

Ferro

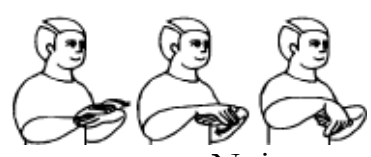

Noite

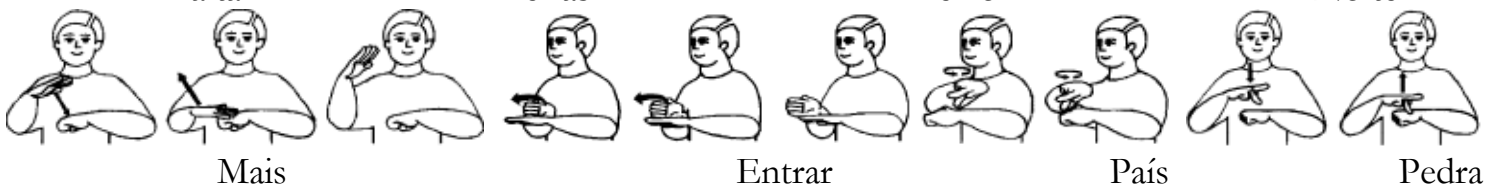

Fonte: elaborado pelos autores com base nos dados desta pesquisa e nas imagens retiradas de Capovilla, Raphael e Maurício (2011).

\section{Os resultados: variação fonológica no subespaço "costas da mão" da Locação "mão de apoio"?}

Para análise dos dados coletados, foi eleita como categoria de análise a forma da mão do subespaço "costas da mão" (se foi configurada mão aberta ou fechada), na qual os 35 sinais foram produzidos pelos 32 sinalizantes surdos da Libras.

De acordo com o quadro 2, constata-se que a maioria dos sinalizantes surdos produzem os sinais realizados no subespaço "costas da mão" com a mão fechada; os 32 sinalizantes usaram a mão de apoio, tanto aberta quanto fechada; não houve nenhum que usasse, em todos os sinais, apenas aberta ou apenas fechada; dos 32 sinais coletados, houve 4 em que os sinalizantes produziram apenas com a mão fechada; dos 32 sinais coletados, não houve nenhum sinal produzido apenas com a mão aberta; houve um sinal que não foi produzido com a mão de apoio no subespaço "costas da mão".

Diante do exposto, constatamos que não há nenhum padrão para que a forma da mão de apoio no subespaço "costas da mão" seja configurada aberta ou fechada pelos sinalizantes surdos na produção dos sinais. Desta forma, para análise da ocorrência da 
variação demonstrada no subespaço "costas da mão" da Locação "mão de apoio", abordamos as noções de alofones.

Os alofones, alofonia ou variação livre são os vários sons que realizam um mesmo fonema, ou seja, um determinado som como variante de um mesmo fonema. Sendo assim, são as realizações fonéticas de um mesmo fonema, e essa variação é condicionada por fatores contextuais (inerentes à vizinhança fonética ou coarticulação), dialetais (em função da variedade geográfica que é falada) ou que simplesmente decorre de opções estilísticas individuais. Essas variações não significam mudanças nas palavras, caracterizando, assim, um alofone. Os alofones são variações diferentes para um mesmo fonema e podem ser classificados em: livres, posicionais e estilísticos.

De acordo com Câmara Jr. (2011), os alofones ou variantes livres dependem dos hábitos de articulação de cada falante, ou seja, quando os falantes da língua divergem na articulação do mesmo fonema ou um mesmo falante muda a articulação conforme o registro em que fala. Sendo assim, em princípio, são possíveis vários alofones para qualquer fonema. Teorias pós-fonêmicas que analisam a variação e mudança linguística demonstram que a "variação livre" na verdade é condicionada por fatores extralinguísticos como localização geográfica, grau de escolaridade, classe social, sexo, idade, entre outros.

Ainda segundo Câmara Jr. (2011), os alofones posicionais ocorrem em virtude da posição que ocupam na cadeia fonológica (classificação segundo articulação, entre outras) e da proximidade dos fonemas vizinhos, ou seja, depende do ambiente fonético em que o som vocal se encontra. Dá-se uma assimilação aos traços dos outros sons contíguos, um afrouxamento ou mesmo mudança de articulações em virtude da posição fraca em que o fonema se acha (por exemplo, nas vogais portuguesas, a posição átona, especialmente em sílaba final). Os alofones estilísticos, de acordo com Câmara Jr. (2011), ocorrem por intenção comunicativa, enriquecendo a articulação de algum traço não habitual. É a variante estilística.

Dentre os três tipos de alofones, os posicionais têm muita importância para caracterizar o conjunto de fonemas da língua. São eles que dão o sotaque da nossa fala, distinguindo, por exemplo, a fala do baiano, do alagoano, do sergipano e assim por diante. Segundo Quadros e Karnopp (2004), a Libras também apresenta dialetos regionais. Mas o que pode ser considerado sotaque na língua de sinais?

As linguistas, professoras e pesquisadoras da Libras Dra. Ronice Müller de Quadros, da Universidade Federal de Santa Catarina (UFSC); Dra. Sueli de Fátima Fernandes, Universidade Federal do Paraná (UFPR); Dra. Walkiria Duarte Raphael, Universidade de São Paulo (USP); Dra. Tanya Amara Felipe dos Santos, Universidade Federal de Pernambuco (UFPE), e Dra. Lodenir Becker Karnopp, Universidade Federal do Rio Grande do Sul, (UFRG) discorrem sobre as variações regionais dessa língua e afirmam ser possível dizer se um surdo é do Sul ou do Nordeste só com base no seu gestual (DEFICIENTE ONLINE, 2018).

De acordo com essas pesquisadoras, o sotaque na Libras é percebido quando os sinais regionais representam a mesma coisa, mas com ponto de articulação, movimentos, direcionalidade e expressões faciais diferentes, ou seja, determinados termos possuem variações maiores ou menores quando "pronunciados" por gestos. A palavra "abacaxi”, por exemplo, nas variantes em forma gestual, tem o mesmo sinal com pequenas mudanças de movimentos entre os compartilhados por Bahia e Pará e os usados no Mato Grosso ou em Santa Catarina. 
A linguista Dra . Ronice Müller de Quadros, coordenadora do curso à distância de Letras Libras na UFSC, afirma que os falantes do Rio de Janeiro costumam usar muito o alfabeto manual na comunicação, ou seja, no lugar do sinal, em muitas situações, o termo é soletrado, uma característica que não é típica dos usuários surdos de São Paulo. A psicóloga $D^{a}$. Walkiria Duarte Raphael diz conseguir identificar um " $R$ " arrastado nos sinais dos surdos cariocas. Segundo a Dr ${ }^{a}$. Walkiria, no Rio de Janeiro se soletra mais arrastado, embora não exista estudo com base científica sobre o assunto. De acordo com a psicóloga, os surdos que oralizam bem (que reproduzem com os lábios as palavras sinalizadas) acabam falando junto com o sinal. E aí é possível perceber claramente o sotaque. A linguista Dra Tanya Amara Felipe dos Santos, que foi coordenadora do Programa Nacional Interiorizando a Libras, afirma que é como se houvesse uma "pronúncia" diferente, um tipo de sotaque sem som.

Segundo a psicóloga Walkiria Duarte Raphael, os surdos do Norte do país se apoiam bastante nas expressões faciais e corporais. De acordo com ela, o tamanho do sinal é maior, ocupa mais espaço, no entanto, esta diferença não tem implicações no significado do sinal. Ela afirma que Manaus é um dos polos em que os estudantes apresentam mais variações. A pesquisadora ainda analisa que, embora não haja equivalência entre o verbo e os sinais de cada lugar, os sotaques dos sinais parecem acompanhar as sutilezas das falas de cada região. Argumenta também que é possível perceber a diferença regional pela observação da mão de apoio. Segundo ela, no Rio de Janeiro, a maioria dos sinais é feita com a mão de apoio fechada, já em São Paulo, a mão de apoio é aberta.

Dentro desta perspectiva, as variações alofônicas que ocorrem na forma da mão de apoio, do subespaço "costas da mão", quando um sinal é produzido sobre ela, são variações que não alteram o sinal, ou seja, não alteram o seu sentido e significado.

Strobel e Fernandes (1998), em suas pesquisas, destacam que os sinais que se referem a variações ${ }^{8}$ na configuração das mãos e/ou no movimento, não modificando o sentido do sinal, são variações sociais, mostrando que a Libras apresenta dialetos regionais.

\section{Considerações finais}

Os resultados deste estudo mostram que as diferentes formas da mão de apoio apresentadas na produção de um mesmo sinal, quando este é produzido nas costas da mão, são variações caracterizadas como sendo resultantes das diferentes manifestações que um sinal pode apresentar na sua produção, sem que isso altere o seu significado.

Embora não haja muitos estudos sobre a variação fonética-fonológica na Libras, observações de usos espontâneos dessa língua não apenas apontam para a sua existência, como também evidenciam que a variação na pronúncia dos sinais pode decorrer das diferentes realizações de suas unidades sublexicais, relacionados à configuração de mão, à localização, ao movimento, à orientação da mão e às marcações não manuais. A variação

\footnotetext{
${ }^{8}$ Sobre variações linguísticas na Libras, Strobel e Fernandes (1998) classificam em regionais, sociais e mudanças históricas. As variações regionais representam as mudanças de sinais de uma região para outra como acontece com os sinais do termo "VERDE" utilizados no Rio de Janeiro, São Paulo e Curitiba. As sociais referem-se às mudanças na configuração de mãos e/ou no movimento, não modificando o sentido do sinal, como no caso do sinal do termo "AJUDAR". E mudanças históricas, pois com o passar do tempo o sinal pode sofrer alterações decorrentes dos costumes da geração que o utiliza, por exemplo, no sinal do termo "AZUL".
} 
linguística no nível fonológico dos sinais ocorre quando há modificação, ao menos em um desses parâmetros.

A unidade linguística é um mito, mesmo nas línguas naturais, e os "sotaques" regionais e as variações lexicais não comprometem em nenhum momento a sua unidade estrutural. No entanto, se fazem necessárias mais pesquisas sobre variações regionais em Libras para que possamos descrever linguisticamente com exatidão as variações nesta língua, tanto no nível fonético-fonológico, quanto no morfossintático e vocabular.

$\mathrm{Na}$ Libras, ainda são poucas as pesquisas sobre variações linguísticas, principalmente no que se refere ao nível fonético-fonológico da língua, embora já exista uma base empírica para os estudiosos e pesquisadores arriscarem algumas configurações. Esta variação, assim como nas línguas orais, pode se manifestar por meio das diferentes realizações de uma ou mais unidades que constituem os seus itens lexicais.

\section{Referências}

BARRETO, Madson; BARRETO, Raquel. Escrita de Sinais sem mistérios. Editora do Autor: Belo Horizonte, 2012.

BATISSON, Robbin. Phonological deletion in American Sign Language. Sign Languages Studies, v. 5, 1974.

BRITO, Lucinda Ferreira et al. Língua brasileira de sinais - LIBRAS. In: BRITO, Lucinda Ferreira et al. (org.). Brasília: Secretaria de Educação Especial, 1998.

CÂMARA Jr., Joaquim Mattoso. Estrutura da Língua Portuguesa. Petrópolis: Vozes, 2011.

CAPOVILLA, Fernando César; MAURÍCIO, Aline Cristina L.; RAPHAEL, Walkiria Duarte. Dicionário enciclopédico ilustrado trilíngue - Novo Deit-LIBRAS - Língua de Sinais Brasileira, 2 volumes. São Paulo: Edusp. 2011.

COSTA, Edivaldo da Silva. O ensino de química e a língua brasileira de sinais sistema SignWriting (Libras-SW): monitoramento interventivo na produção de sinais científicos. 2014. Dissertação (Mestrado em Ensino de Ciências e Matemática) - Programa de Pós-graduação em Ensino de Ciências e Matemática, Universidade Federal de Sergipe, São Cristóvão, 2014.

DEFICIENTE ONLINE. O mercado de emprego para deficientes auditivos cresce no Brasil. [2018]. Disponível em: http://www.deficienteonline.com.br/os-sotaques-dossinais-libras-de-um-jeito-diferente_news_5.html. Acesso em: 4 jun. 2019.

FELIPE, Tânia Amara. Introdução à gramática da Libras (Série Atualidades Pedagógicas). Brasília: Secretaria de Educação Especial, 1998.

FERREIRA-BRITO, Lucinda; LANGEVIN, R. Sistema Ferreira Brito-Langevin de transcrição de sinais. In: FERREIRA-BRITO, Lucinda. Por uma gramatica de língua de sinais. Rio de Janeiro: Babel, 1995. 
KARNOPP, Lodenir Becker. Aquisição fonológica da Língua Brasileira de Sinais: estudo longitudinal de uma criança surda. 1999. Tese (Doutorado em Letras) - Pontifícia Universidade Católica do Rio Grande do Sul, Porto Alegre, 1999.

KLIMA, Edwards S.; BELLUGI, Ursulla. The signs of language. Cambridge: Cambridge University Press, 1979.

QUADROS, Ronice Müller; KARNOPP, Lodenir Becker. Língua de sinais brasileira: estudos lingüísticos. Porto Alegre: Artmed, 2004.

STOKOE, William C. Sign Language structure: an outline of the visual communication systems of the American deaf. Studies in linguistics: occasional papers, Buffalo, n. 8, 1960.

STROBEL, Karin Lilian; FERNANDES, Sueli. Aspectos linguísticos da língua brasileira de sinais. Curitiba: Secretaria de Educação; Superintendência de Educação; Departamento de Educação Especial, 1998.

SUTTON, Valerie. Lesssons in SignWriting: textbook \& workbook. 3. ed. La Jolla: Center for Sutton Movement Writing, 2003.

XAVIER, André Nogueira. Descrição fonético-fonológica dos sinais da língua brasileira de sinais (LIBRAS). 2006. Dissertação (Mestrado em Linguística) - Faculdade de Filosofia e Ciências Humanas, Universidade de São Paulo, São Paulo, 2006.

XAVIER, André Nogueira; BARBOSA, Plínio Almeida. Diferentes pronúncias em uma língua de sinais? Um estudo da variação na produção de sinais da Libras. Delta Documentação e Estudos em Linguística Teórica e Aplicada, São Paulo, v. 30, n. 2, p. 371 413, 2014. 